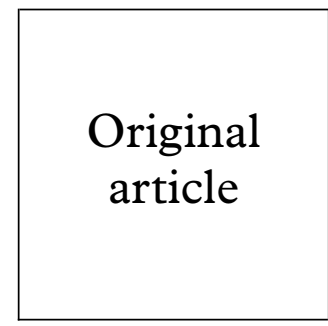

\title{
Role of type specific herpes simplex virus serology in the diagnosis and management of genital herpes
}

\author{
P E Munday, J Vuddamalay, M J Slomka, D W G Brown
}

\begin{abstract}
Objectives: To investigate the indications for the use of a type specific antibody test for herpes simplex virus in a department of genitourinary medicine in the United Kingdom

Method: Retrospective analysis of case records of 127 patients who accepted the test during a 20 month period.

Results/conclusion: The test contributed to patient management in $79 \%$ of patients with recurrent genital ulceration of unknown cause. It was also useful for counselling a number of patients with initial episodes of disease and the asymptomatic partners of some patients when the partners were shown to possess antibodies specific to herpes simplex virus type 2 . When evaluating sexual partners, the test was difficult to interpret if an isolate from the index case had not been typed. Access to viral typing may therefore be a greater priority than serological testing. As adverse psychological sequelae may follow the identification of an asymptomatic chronic infection, guidelines for the use of a type specific serological test are proposed.

(Sex Transm Inf 1998;74:175-178)
\end{abstract}

Keywords: herpes simplex virus; type specific serology

\section{Introduction}

There were more than 27000 cases of genital herpes reported in 1995 and infection is becoming more common. ${ }^{1}$ The proportion of cases of first episode genital herpes infections due to herpes simplex virus (HSV) types 1 and 2 seems to show a marked variation ${ }^{2-4}$ and in several British centres, $50 \%$ or more of cases in women have been shown to be due to HSV $-1 .{ }^{56}$

Primary genital herpes, caused by HSV type 1 or type 2 , presents as severe genital ulceration associated with a systemic illness, whereas recurrent episodes are generally mild and short lived. Although episodes of genital herpes caused by HSV-1 and HSV-2 are clinically indistinguishable, there is evidence that both symptomatic and asymptomatic recurrences are less frequent after HSV-1 genital infection. ${ }^{7}$ Furthermore, first episode HSV-2 genital infection in an individual who already has antibody to HSV-1, may be less severe than in a true primary episode. ${ }^{2}$ Koutsky et al ${ }^{9}$ have drawn attention to the atypical appearances of many disease episodes in women, raising the question of a possible diagnosis of genital herpes in a wide range of clinical situations. Furthermore, the first clinical episode may be delayed and may occur some time after acquisition of the virus. ${ }^{10}$ Recently, it has been shown that most people infected with HSV-2 are asymptomatic or have atypical symptoms ${ }^{9}$ and are thus unaware of their infection. This may result in the unwitting infection of sexual partners and Mertz et $a l^{11}$ have shown that up to $70 \%$ of new genital herpes infections may be acquired in such circumstances.

Once the possibility of a herpes infection has been raised with a patient it can be impossible to dispel concerns, even if repeated attempts at viral identification are negative. The ability effectively to exclude HSV infection by demon- strating the absence of HSV antibody could be potentially useful; conversely, finding HSV antibody, especially type 2, would strengthen or confirm the diagnosis in many cases. Furthermore, it may be difficult to answer questions about the likely source of their infection and the risk of transmission to a regular sexual partner. Knowledge of the serotype of any isolate is helpful but counselling would be enhanced by information about the source and partner's previous exposure to herpes simplex viruses by the presence of type specific antibody. Since most adults possess HSV type 1 antibody as a result of childhood infection, any antibody test for use in the management of genital herpes should be type specific.

HSV type specific antibody is usually detected within 8 weeks of onset. ${ }^{12-14}$ Thus, serum obtained from a patient during a true primary episode is very likely to be type specific antibody negative and type specific antibody of either type in a patient during a first episode implies a high likelihood of previous infection with HSV and such an episode is classified as initial rather than primary disease (table 1). In the case of recurrent genital ulceration from which an isolate has not been obtained, the presence of HSV 2 antibody adds strength to the diagnosis of recurrent HSV-2 disease (although other causes of genital ulceration may occur even in the presence of HSV-2 antibody).

Most currently available commercial HSV antibody assays do not distinguish reliably between antibody responses to $\mathrm{HSV}-1$ and HSV-2 ${ }^{15}$ However, new type specific commercial assays for HSV-2 specific antibodies are becoming available and may be used in a variety of clinical settings. We report here an evaluation of HSV type specific serology over a 20 month period in a genitourinary medicine clinic. 
Table 1 Interpretation of laboratory tests for HSV in patients with first episodes of genital ulceration

\begin{tabular}{|c|c|c|c|c|}
\hline \multirow[b]{2}{*}{$\begin{array}{l}\text { Antibody } \\
\text { detected }\end{array}$} & \multicolumn{4}{|l|}{ Result of viral detection } \\
\hline & HSV-1 detected & $H S V-2$ detected & $\begin{array}{l}\text { HSV detected; } \\
\text { type unknown }\end{array}$ & $\begin{array}{l}\text { HSV EIA or culture } \\
\text { negative (or no test) }\end{array}$ \\
\hline HSV-1 Ab & Initial type $1 \mathrm{GH}^{\star}$ & Initial type $2 \mathrm{GH}$ & initial GH & uninterpretable \\
\hline $\mathrm{HSV}-2 \mathrm{Ab}$ & Initial type $1 \mathrm{GH}$ & Initial type $2 \mathrm{GH}$ & initial GH & $\begin{array}{l}\text { probable initial type } \\
2 \mathrm{GH}\end{array}$ \\
\hline $\mathrm{HSV}-1+2 \mathrm{Ab}$ & initial type $1 \mathrm{GH}$ & initial type $2 \mathrm{GH}$ & initial GH & probable initial $\mathrm{GH}$ \\
\hline Seronegative & primary type $1 \mathrm{GH}$ & primary type $2 \mathrm{GH}$ & primary GH & uninterpretable \\
\hline
\end{tabular}

${ }^{\star} \mathrm{GH}=$ genital herpes.

\section{Methods}

During the period of the study, an enzyme immunoassay (EIA; Wellcozyme HSV; Murex Biotech) was used in the department of genitourinary medicine of Watford General Hospital for the routine identification of HSV from lesions, though viral culture and serotyping were available for special cases.

Type specific serology was performed using a monoclonal antibody blocking assay as previously described..$^{13}$ Equivocal sera for HSV type specific antibody were those where the percentage blocking value was within $5 \%$ of the positive/negative cut offs established previously ${ }^{13}$ and which did not resolve on repeat testing. Sera were stored at $-20^{\circ} \mathrm{C}$ until testing.

Clinicians were offered the type specific HSV antibody test to use according to their clinical judgment but were advised of appropriate situations when it might be useful. Such circumstances might be when a patient had undiagnosed recurrent ulceration or atypical lesions from which an EIA or culture was negative, or when the asymptomatic partner of an infected patient attended. The guidelines did not include first episodes of disease as it was unlikely that such patients would have a type specific humoral response to a true primary HSV infection at the time of presentation. However, 31 of the 273 (11\%) first episodes seen during the study period were assessed to ascertain whether the information might be useful in counselling. It was anticipated that in some cases, particularly when there had been a number of episodes of recurrent ulceration, the absence of any HSV antibody might allow a clinician to confidently exclude HSV as the cause of the symptoms. Patients were informed that the test was a research test but that a previous study ${ }^{13}$ had confirmed a high correlation with the western blot assay, the "gold standard" test. ${ }^{12}$

After 20 months, the indications for its use, the results, and the benefits obtained were reviewed. Each test result was classified as

(1) diagnostic (if the test was the means by which the final diagnosis was achieved or excluded)

(2) useful for counselling (if it generated information not available from other sources)

(3) contributory to a diagnosis

(4) non-contributory.

\section{Results}

All 127 patients who were offered and accepted the HSV-1 and 2 antibody test between 21 September 1994 and 31 May 1996 were studied.
Forty nine patients were found to have antibody to HSV-1 only, seven to HSV-2 only, 43 to both serotypes (designated "seropositive"), and 26 to neither (designated "seronegative"). Only two sera gave equivocal results in testing for type specific humoral responses-namely, those of one man who had an equivocal HSV-1 antibody test (and HSV-1 isolated from lesions) and another man who was equivocal for HSV-2 antibody and subsequently seroconverted. In this selected population, therefore, the HSV-1 and HSV-2 seroprevalences were $72.4 \%$ and $39.4 \%$ respectively. A second specimen was available in 19 cases (obtained between 42 and 234 (median 114) days after the initial specimen) and in three cases seroconversion to HSV-1 and in two cases seroconversion to HSV-2 were demonstrated.

\section{PATIENTS WITH FIRST EPISODES OF GENITAL}

ULCERATION

Twenty nine patients (23 men and six women) were tested during their first episode of genital ulceration. Fifteen men had positive and six men negative EIA results and two were not tested by EIA. Type specific antibody results for these men are shown in table 2 and from these findings it was possible to classify four men as having a primary infection and 14 men as probably having initial clinical episodes. Three patients had lesions which were EIA negative but had HSV-2 type specific antibody confirming the diagnosis of initial genital herpes. In the other five of the eight cases who did not have a positive EIA, serology did not provide any useful information. An additional two men (not shown in table 2) were tested after single episodes of genital ulceration, 3 weeks and 3 months previously. Both had HSV-1 antibody and the test was thus diagnostically unhelpful.

Of the six women, two had atypical lesions but EIA tests were unexpectedly positive. One of these women was seropositive (probable initial episode) and the other seroconverted to HSV-2 (true primary infection). A third woman with very severe ulceration who was known to have had severe HSV-1 encephalitis previously, had HSV-1 isolated from her genital lesions and had HSV-1 antibody. Three women, all of whom had atypical lesions, did not have EIA tests performed. One of these seroconverted to HSV-1 establishing the diagnosis of primary HSV-1 infection; the test was therefore diagnostically helpful in this one instance. The other two women had HSV 1

Table 2 Evaluation of men with first episodes of genital ulceration

\begin{tabular}{lllll}
\hline $\begin{array}{l}\text { Type specific } \\
\text { antibody }(A b) \\
\text { present }\end{array}$ & \multicolumn{4}{l}{ HSV EIA result } \\
\cline { 2 - 5 } & Positive & Negative & Not done & Total \\
\hline HSV-1 Ab & $\begin{array}{c}4(+1 \\
\text { equivocal) } \dagger\end{array}$ & 2 & 0 & 7 \\
HSV-2 $\mathrm{Ab}$ & 0 & $1 \dagger$ & 0 & 1 \\
HSV-1 and 2 Ab & $6 \dagger$ & $2 \dagger$ & 0 & 8 \\
Seronegative & $4^{\star}$ & 1 & 2 & 7 \\
Total & 15 & 6 & 2 & 23
\end{tabular}

^ Probable primary genital herpes.

†Initial genital herpes. 
antibody only and the test was diagnostically unhelpful.

Overall, for patients with first episodes of genital ulceration, the test was diagnostically helpful in four patients (13\%) useful for counselling in $18(58 \%)$, and was non-contributory in nine $(29 \%)$ cases. However, the four patients for whom the test was diagnostically useful comprised $31 \%$ of those 13 who did not have a positive viral identification test.

\section{PATIENTS WITH UNDIAGNOSED RECURRENT}

GENITAL ULCERATION

Thirty nine patients, 17 men and 22 women, were tested because they had had episodes of recurrent genital ulceration in the past; in all cases, viral identification tests (on one or more occasions) had been negative. In 22 cases, eight men and 14 women, the diagnosis of genital herpes was supported by the presence of HSV-2 antibody. Five men and four women (one of whom was pregnant) were seronegative and the diagnosis was therefore excluded. Four men and four women had HSV-1 antibody only and thus the test was diagnostically unhelpful.

Overall the test was diagnostically useful in $31(79 \%)$ and non-contributory in eight $(21 \%)$ patients with recurrent undiagnosed genital ulceration.

\section{SEXUAL PARTNERS OF PATIENTS WITH GENITAL} HERPES

Twenty nine patients, 18 men and 11 women, were tested because a current or former sexual partner had genital herpes. Three men and three women, who had no history of genital herpes, had HSV-2 antibody and were assumed to be asymptomatic carriers of the virus. Eleven men and seven women had HSV-1 antibody only. These clients were considered to be possible sources of their partners' genital tract infection and counselled accordingly; typing of the index patients' isolates would have been helpful but without this information these results were uninterpretable. Interestingly, four of these men had symptomatic female partners who were found to have HSV-2 antibody, and thus these men were susceptible to HSV-2 genital infection. Four men and one woman were seronegative and were therefore at risk of acquiring their partner's genital infection.

Overall, the test was useful for diagnosis in six $(21 \%)$, for counselling in nine $(31 \%)$, and was non-contributory in $14(48 \%)$ cases when partners were tested.

\section{MISCELLANEOUS INDICATIONS}

Four men were tested because they had non-ulcerative balanitis, three men and one woman because they had penile or vulval oedema or lymphadenopathy, and four people because of oral lesions. In only two cases were serological diagnoses achieved; one man had penile oedema and lymphadenopathy but no ulceration and another had severe oral ulceration, and both seroconverted to HSV-1. In all other cases the test was not diagnostic but in some cases added weight to an alternative diagnosis. Other miscellaneous indications included atypical nerve pain in a lower limb, scrotal ulceration, lesions suggestive of erythema multiforme, and a vague history of contact with a woman "who had something". In all these cases, the antibody tests helped to support the impression that the complaints were not manifestations of genital herpes.

One woman had clitoral soreness which made examination very difficult but possible ulceration was noted. She was found to be seropositive and despite extensive pretest and post-test counselling responded very badly with the break up of her relationship as a consequence of the diagnosis. She subsequently failed to respond to aciclovir suppression and a final diagnosis of dysaesthetic vulvodynia was made. Another woman was referred because a cervical smear had shown changes suggestive of HSV. She had had a previous episode of undiagnosed genital ulceration and was found to be seropositive, a result which was helpful in confirming the diagnosis.

In four cases there was no obvious clinical indication for carrying out the test and in six cases the diagnosis of genital herpes had already been established by viral identification; thus in these 10 cases, no justification for type specific serology could be made.

\section{Discussion}

Type specific serology tests for herpes simplex viruses have been used as research tools in seroepidemiological studies for some years. ${ }^{16-18}$ Commercially available test systems are being marketed but their clinical uses have not been evaluated. Since the results of studies have indicated a large pool of infected individuals ${ }^{17}{ }^{18}$ who are presumably asymptomatic, there has been concern about the psychological and psychosocial sequelae of identifying asymptomatic infections in such individuals when there is no prospect of cure. ${ }^{19}$ Many clinicians however believe there are cases in which testing could be useful and in a recent study of unselected attenders at a genitourinary medicine clinic $^{20}$ most patients who were surveyed indicated that they would like to have the test. We have evaluated the use of the test in a number of clinical situations in order to formulate guidelines for its most appropriate use.

In our hands (table 3 ) we found that the test was most useful for investigating patients who had recurrent genital ulceration as a diagnosis was achieved in $79 \%$ of cases. Some of these patients had made numerous visits to the clinic but a positive identification test had never been obtained. This may have been because of the relative insensitivity of the diagnostic test in use (EIA) for recurrent ulceration. ${ }^{21}$ The ability to achieve a firm diagnosis whether positive or negative and to initiate suppressive therapy if appropriate was welcomed by patients. However, the test was inconclusive if HSV-1 antibody only was detected.

In the case of first episodes of genital ulceration, it was often possible to distinguish between a true primary episode and an initial episode. Some patients who were in stable relationships were reassured to know that they had HSV-2 antibody at their first presentation 
Table 3 Value of type specific HSV serology in relation to indication for testing in 117 genitourinary medicine clinic attenders

\begin{tabular}{lccccc}
\hline \multirow{2}{*}{ Indication $^{*}$} & \multicolumn{2}{c}{ Contribution of test result to patient management } \\
\cline { 2 - 6 } & Diagnostic & Counselling & Contributory & Non-contributory & Total \\
\hline First episode & 4 & 18 & 0 & 9 & 31 \\
Recurrent & 31 & 0 & 0 & 8 & 39 \\
Partners & 6 & 9 & 0 & 14 & 29 \\
Miscellaneous & 3 & 0 & 5 & $9(+1 \dagger)$ & 18 \\
Total & 44 & 27 & 5 & 41 & 17 \\
\hline
\end{tabular}

$\star$ For precise description see text.

IIn this case, the test was unhelpful as it caused adverse psychological sequelae.

and were therefore likely to have had the infection for some time. In other cases, the identification of HSV-2 antibody in an asymptomatic partner provided a possible explanation for the source of the infection in the index case. Thus in this setting the test was more useful for counselling patients than for providing conclusive diagnostic information.

The identification of HSV-1 antibody was generally unhelpful, as it was usually not possible to know whether this represented genital or oral disease. Had it been possible to type index patients' isolates, the identification of HSV-1 antibody in the partner of a patient with HSV-1 genital herpes would have been helpful as it would suggest orogenital acquisition. ${ }^{7}$ However, genital to genital transmission of HSV-1 may take place. Further knowledge of the transmission dynamics of $\mathrm{HSV}-1$ is required in the light of the increasing prevalence of this virus in the genital tract. This highlights the contribution to patient management of subtyping HSV strains identified in genital herpes in communities with changing patterns of infection. In such circumstances, the ability to type isolates may be more valuable than type specific serological tests, and departments which do not have access to typing should seek to introduce this before considering the use of serological tests.

In the small group of patients studied, we did not feel that the test was useful in evaluating patients with atypical, non-ulcerative symptoms, especially when there had only been one episode. Most of these patients had HSV-1 antibody. The test was used on four occasions to investigate oral symptoms and it was possible to confirm a primary HSV pharyngitis in one case.

Table 4 Proposed indications for the use of an HSV type specific antibody test

(1) Diagnosis or exclusion of HSV as the cause of recurrent genital ulceration where the key test is for HSV-2 specific antibody.

(2) Counselling of couples who have concerns about the source of an HSV infection or the risk of transmission.

(3) Evaluation of patients with symptoms very suggestive of genital herpes, from whom a diagnostic test cannot be obtained (for example, if already on treatment).

Caveats

(1) Pretest counselling is required (guidelines need to be developed).

(2) The patient should be told that the test may not contribute to his/her diagnosis or management.

(3) Further evaluation of the advantages and disadvantages of offering the test to those seeking an STD screen, who have no history of or contact with genital herpes, is required.
We believe that it is important to establish guidelines for the appropriate use of this test as it becomes more widely available (table 4 ). If it were promoted as a routine screening test (like serological tests for syphilis) a positive result could cause considerable damage to a relationship and to an individual's self esteem. Clearly the use of a diagnostic test for a condition which, although not life threatening, is incurable, requires pretest counselling and facilities for follow up and support. Further research on the advantages and disadvantages of its use in these circumstances should include objective measures of outcome such as psychological assessment.

The authors thank the staff of the Department of Genitourinary Medicine at Watford General Hospital for the collection of specimens and provision of clinical data.

Individual contributions from authors not available.

1 Department of Health. Sexually transmitted diseases, England 1995. Bulletin 1996/14. London: DoH.

2 Corey L, Adams HG, Brown ZA, et al. Genital herpes simplex virus infections: clinical manifestations, course and complications. Ann Intern Med 1983;98:958-72.

3 Tardieu JC, Friedel J. Incidence of herpes simplex virus types 1 and 2 in herpes genitalis in Strasbourg, France. $B r$ f Vener Dis 1983;59:138.

4 Löwhagen G-B, Jansen E, Nordenfelt E, et al. Epidemiology of genital herpes infections in Sweden. Acta Derm Venereol (Stockh) 1990;70:330-4

5 Barton IG, Kinghorn GR, Najem S, et al. Incidence of herpes simplex virus types 1 and 2 isolated in patients with herpes genitalis in Sheffield. Br $\mathcal{F}$ Vener Dis 1982;58:44-7.

6 Tayal SC, Pattman R. High prevalence of herpes simplex virus type 1 in female anogenital herpes simplex in
Newcastle upon Tyne 1983-1992. Int $\mathscr{f}$ STD AIDS 1994;5:359-61.

7 Lafferty WE, Coombs RW, Benedetti J, et al. Recurrences after oral and genital herpes simplex virus infection. $N$ Engl J Med 1987;316:1444-9.

8 Koelle DM, Benedetti J, Langenberg A, et al. Asymptomatic reactivation of herpes simplex virus in women after the first episode of genital herpes. Ann Intern Med 1992;116:433-7.

9 Koutsky LA, Stevens CE, Holmes KK, et al. Underdiagnosis of genital herpes by current clinical and viral-isolation procedures. N Engl F Med 1992;326:1533-9.

10 Bernstein DI, Lovett MA, Bryson YJ. Serological analysis of first-episode nonprimary genital herpes simplex virus infection. Am 7 Med 1984;77:1055-60.

11 Mertz GJ, Benedetti J, Ashley R, et al. Risk factors for the sexual transmission of genital herpes. Ann Intern Med 1992;116:197-202.

12 Ashley RL, Militoni J, Lee F, et al. Comparison of western blot (immunoblot) and glycoprotein G-specific immunodot enzyme assay for detecting antibodies to herpes simplex virus types 1 and 2 in human sera. $\mathcal{F}$ Clin Microbiol 1988;26:662-7.

13 Slomka MJ, Ashley RL, Cowan FM, et al. Monoclonal antibody blocking tests for the detection of HSV-1- and HSV-2- specific humoral responses: comparison with western blot assay. $\mathcal{F}$ Virol Methods 1995;55:27-35.

14 Ho DWT, Field PR, Irving WL, et al. Detection of immunoglobulin $M$ antibodies to glycoprotein $G-2$ by western blot (immunoblot) for diagnosis of initial herpes western blot (immunoblot) for diagnosis of initial herpes
simplex virus type 2 genital infections. F Clin Microbiol simplex virus type

15 Ashley R, Cent A, Maggs V, et al. Inability of enzyme immunoassays to discriminate between infections with herpes simplex virus types 1 and 2. Ann Intern Med 1991;115:520 6.

16 Slomka MJ. Seroepidemiology and control of genital herpes:the value of type-specific antibodies to herpes simplex virus. CDR Review 1996;6:R41-5.

17 Johnson RE, Nahmias AJ, Magder LS, et al. A seroepidemiologic survey of the prevalence of herpes simplex virus type 2 infection in the United States. $N$ Engl $f \mathrm{Med}$ 1989;321:7-12.

18 Cowan FM, Johnson AM, Ashley R, et al. Antibody to herpes simplex virus type 2 as serological marker of sexual lifestyle in populations. BMF 1994;309:1325-9.

19 Mindel A. Psychological and psychosexual implications of herpes simplex virus infections. Scand 7 Infect Dis (Suppl) 1996;100:27-32.

20 Fairley I, Monteiro EF. Patient attitudes to type-specific serological tests in the diagnosis of genital herpes. Genitourin Med 1997;73:259-62.

21 Slomka MJ, Emery L, Munday PE, et al. A comparison of PCR with virus isolation and direct antigen detection for diagnosis and typing of genital herpes. $f$ Med Virol (in press). 